\title{
Transgenic expression of haem oxygenase- 1 in pancreatic beta cells protects non-obese mice used as a model of diabetes from autoimmune destruction and prolongs graft survival following islet transplantation
}

\author{
S. H. Huang • C. H. Chu • J. C. Yu • W. C. Chuang • \\ G. J. Lin • P. L. Chen • F. C. Chou • L. Y. Chau • \\ H. K. Sytwu
}

Received: 11 February 2010 /Accepted: 5 July 2010 /Published online: 5 August 2010

(C) Springer-Verlag 2010

\begin{abstract}
Aims/hypothesis Haem oxygenase 1 (HO-1) has strong anti-apoptotic, anti-inflammatory and antioxidative effects that help protect cells against various forms of immune attack. We investigated whether transgenic expression of Ho-1 (also known as Hmoxl) in pancreatic beta cells would
\end{abstract}

\section{S. H. Huang}

Graduate Institute of Medical Sciences,

National Defense Medical Center,

Taipei, Taiwan, Republic of China

S. H. Huang • C. H. Chu • J. C. Yu

Department of General Surgery, Tri-Service General Hospital,

Taipei, Taiwan, Republic of China

W. C. Chuang - P. L. Chen · F. C. Chou $\cdot$ H. K. Sytwu

Graduate Institute of Life Sciences,

National Defense Medical Center,

Taipei, Taiwan, Republic of China

\section{G. J. Lin}

Department of Biology and Anatomy,

National Defense Medical Center,

Taipei, Taiwan, Republic of China

\section{Y. Chau}

Institute of Biomedical Sciences, Academia Sinica,

Taipei, Taiwan, Republic of China

H. K. Sytwu ( $\square)$

Department of Microbiology and Immunology,

National Defense Medical Center,

No. 161, Section 6, MinChuan East Road,

Neihu, Taipei, Taiwan 114

e-mail: sytwu@ndmctsgh.edu.tw protect NOD mice from autoimmune damage and prolong graft survival following islet transplantation.

Methods To evaluate the protective effect of beta cellspecific HO-1 in autoimmune diabetes, we used an insulin promoter-driven murine $H o-1$ construct ( $\mathrm{p} I n s-\mathrm{mHo}-\mathrm{l}$ ) to generate a transgenic NOD mouse. Transgene expression, insulitis and the incidence of diabetes in mice were characterised. Lymphocyte composition, the development of T helper (Th)1, Th2 and T regulatory (Treg) cells, T cell proliferation and lymphocyte-mediated disease transfer were analysed. The potential effects of transgenic islets and islet transplantation on apoptosis, inflammation and the generation of reactive oxygen species (ROS) and reactive nitrogen species (RNS) were evaluated.

Results Transgenic mice showed less severe insulitis and a lower incidence of diabetes than non-transgenic control littermates. Lymphocyte composition and functions were not affected. Islets from transgenic mice expressed lower levels of proinflammatory cytokines/chemokines, proapoptotic gene expression and amounts of ROS/RNS, and were more resistant to TNF- $\alpha$ - and IFN- $\gamma$-induced apoptosis. Islet grafts from transgenic mice also survived longer in diabetic recipients than control islets.

Conclusions/interpretation Transgenic overexpression of Ho- 1 in beta cells protected NOD mice from diabetes and delayed the autoimmune destruction of islet grafts, providing valuable insight into the development of better strategies for clinical islet transplantation in patients with type 1 diabetes.

Keywords Heme oxygenase $1 \cdot$ NOD mice Type 1 diabetes 


$\begin{array}{ll}\text { Abbreviations } \\ \text { AAD } & \text { Amino-actinomycin D } \\ \text { CoPP } & \text { Cobalt protoporphyrin } \\ \text { FOXP3 } & \text { Forkhead box P3 } \\ \text { GFP } & \text { Green fluorescent protein } \\ \text { HO-1 } & \text { Haem oxygenase 1 } \\ \text { iDCs } & \text { Immature dendritic cells } \\ \text { IHC } & \text { Immunohistochemical } \\ \text { IkB } & \text { Inhibitory protein of NF-kB } \\ \text { mHo-1 } & \text { Murine Ho-1 } \\ \text { NDMC } & \text { National Defense Medical Center } \\ \text { NF-kB } & \text { Nuclear factor kappa-light-chain-enhancer of } \\ & \text { activated B cells } \\ \text { pIns-mHo-1 } & \text { Insulin promoter-driven murine HO-1 } \\ & \text { construct } \\ \text { ROS } & \text { Reactive oxygen species } \\ \text { RNS } & \text { Reactive nitrogen species } \\ \text { STAT-1 } & \text { Signal transducer and activator of } \\ & \text { transcription-1 } \\ \text { Th } & \text { T helper } \\ \text { Thy1 } & \text { Human Thy-1 cell surface antigen } \\ \text { Thy1.1 } & \text { Mouse thymus cell antigen 1, theta } \\ \text { Treg } & \text { T regulatory }\end{array}$

\section{Introduction}

Autoimmune destruction of beta cells in the pancreatic islets of Langerhans leads to type 1 diabetes mellitus [1]. The NOD mouse is an inbred strain that spontaneously develops autoimmune diabetes resembling human type 1 diabetes $[2,3]$. Destruction of beta cells is caused by the release of inflammatory cytokines and cytotoxic molecules, such as IL- $1 \beta$, IFN- $\gamma$, TNF- $\alpha$, granzyme B and perforin, or by directly inducing downstream cell death signals of the Fas-Fas ligand pathway through natural killer cells, macrophages, pathogenic $\mathrm{T}$ helper (Th) 1 cells and cytotoxic $\mathrm{T}$ cells. In addition, levels of intracellular nitric oxide, reactive oxygen species (ROS) and reactive nitrogen species (RNS) can be induced by these different reactive pathways and also damage beta cells [4-7].

Haem oxygenase-1 (HO-1) is an inducible intracellular enzyme, which is produced at high levels in the spleen, liver and kidney, and catabolises the haem component of haemoglobin from senescent erythrocytes. HO-1 can break the porphyrin ring of haem to yield equal molar amounts of biliverdin, free iron and carbon monoxide [8]. HO-1 also possesses critical cytoprotective functions that are activated under cellular stress situations, such as inflammation, ischaemia, hypoxia, hyperoxia, hyperthermia or radiation [9]. HO-1 exerts major cytoprotective functions against inflammation, apoptosis and oxidative damage, and acts in the maintenance of microcirculation [10]. Accumulating evidence indicates that HO-1 plays an important role in immune regulation. Thus, immature dendritic cells (iDCs) spontaneously produce HO-1, which is downregulated by maturation stimuli such as lipopolysaccharide. Induction of HO-1 production rendered iDCs refractory to lipopolysaccharide-induced maturation, but preserved IL-10 secretion, suggesting that HO-1 plays an important role in the maturation and function of iDCs, and could be used to modulate the immune response [11]. Splenocytes from Ho-1 (also known as Hmoxl) knockout mice secreted disproportionately high levels of Th1 cell-associated and proinflammatory cytokines on stimulation, implying a critical regulatory role of HO-1 in Th1/Th2 balance and early inflammatory responses [12]. In addition, Foxp 3 and Ho- 1 are coexpressed in human peripheral $\mathrm{CD}^{+} \mathrm{CD} 25^{+} \mathrm{T}$ regulatory (Treg) cells and the suppressive function of the cells is abrogated by inhibition of HO-1 activity [13]. Moreover, adeno-associated virusmediated overexpression of $\mathrm{Ho}-1$ protected NOD mice from autoimmune diabetes by reducing the population of mature dendritic cells and autoreactive $\mathrm{T}$ lymphocytes, providing a successful preventive strategy for systemic Ho- 1 expression in this disease [14]. Induction or overexpression of $\mathrm{Ho}-\mathrm{I}$ also successfully prolonged survival of transplanted grafts following allotransplantation of the heart [15], liver [16], thyroid [17] and islets [18]. However, it remains unclear whether HO-1 has a protective effect on pancreatic beta cells in NOD mice.

To investigate the protective potential of beta cell-specific overexpression of Ho- $\mathrm{l}$ in NOD mice and its ability to counter autoimmune attack in syngeneic islet transplantation, we generated murine Ho- 1 ( $\mathrm{mHo}-1)$-transgenic NOD mice, which overproduce HO-1 under the control of the human insulin promoter. The expression of transgenic Ho- $\mathrm{H}$ in beta cells significantly ameliorated the severity of insulitis and the incidence of diabetes in NOD mice, and increased survival of islet grafts. Although local and persistent HO-1 production did not alter systemic immunity, it mediated against inflammation and apoptosis, and reduced levels of ROS/RNS in islets. Furthermore, transgenic islet grafts successfully delayed recurrence of autoimmunity. Thus, for the first time, we have demonstrated the protective potential of transgenic Ho-l in islets in this animal model of autoimmune diabetes, providing a potential therapeutic strategy using tissue-specific genetic manipulation.

\section{Methods}

Cells and animals NIT-1 is an insulinoma cell derived from NOD mice and was purchased from the American Type Culture Collection (Manassas, VA, USA). The NOD/Sytwu $\left(\mathrm{K}^{\mathrm{d}}, \mathrm{D}^{\mathrm{b}}, \mathrm{L}^{\mathrm{d}}, \mathrm{I}-\mathrm{A}^{\mathrm{g} 7}\right)$ mice were originally purchased from Jackson Laboratory (Bar Harbor, ME, USA). NOD.CB17- 
$\mathrm{Prkdc}^{\text {scid } / \mathrm{J}}$ (NOD/SCID) mice were provided by the National Laboratory Animal Center (Taipei, Taiwan). All mice were bred and maintained under specific pathogenfree conditions at the Animal Center of the National Defense Medical Center (NDMC) (Taipei, Taiwan), which is accredited by Association for Assessment and Accreditation of Laboratory Animal Care International. Experiments were conducted in accordance with institutional guidelines and were approved by NDMC's Institutional Animal Care and Use Committee.

Generation and detection of transgenic NOD mice To generate transgenic mice, we used an insulin promoterdriven $\mathrm{mHo}-1$ construct ( $\mathrm{p}$ Ins- $\mathrm{mHo}-1$ ) that was created by inserting cDNA into the pIns-plasmid under the control of a modified human insulin promoter.

Immunohistochemical analysis Tissue sections were probed with a rat anti-mouse HO-1 monoclonal antibody (eBioscience, San Diego, CA, USA), an anti-insulin monoclonal antibody (eBioscience) and an anti-Ki67 antibody (Abcam, Cambridge, UK), followed by a horseradish peroxidase-conjugated secondary antibody. Aminoethyl-carbazole reagent (DAKO, Carpinteria, CA, USA) was added for enzymatic stain development and Mayer's haematoxylin was applied as a counterstain.

Assessment of insulitis and diabetes Pancreatic tissues were obtained from 14-week-old transgenic or non-transgenic mice and the severity of insulitis was scored on haematoxylineosin stained sections and classified as described [19]. Urine glucose concentration was measured weekly using Chemstrips (Boehringer Mannheim, Indianapolis, IN, USA). Mice with urine glucose concentration $>27.75 \mathrm{mmol} / \mathrm{l}$ at two consecutive tests were defined as diabetic.

Islet isolation and transplantation Pancreatic islets were isolated and transplanted into recipients as described in previous reports [20-23]. The success rate for transplantation, any recurrence of diabetes or loss of graft function were defined as described [21].

Flow cytometry Flow cytometric analysis was performed as previously described $[20,21,23]$.

Tcell proliferation Splenocytes were isolated from 8-weekold $\mathrm{mHo}$-1-transgenic or non-transgenic mice. T cell proliferation was performed as previously described [20, 23].

Adoptive transfer Splenocytes of female $\mathrm{mHo}$-1-transgenic or non-transgenic donor mice (12-week-old) were treated with Tris-buffered ammonium chloride for erythrocyte depletion and $2 \times 10^{7}$ cells were injected into female NOD/
SCID mice (6-week-old) via the retro-orbital plexus. Diabetes was assessed as described above.

Real-time RT-PCR Real-time RT-PCR was performed using PCR supermix (iQ SYBR Green; Bio-Rad, Hercules, CA, USA) in an iCycler (Bio-Rad) as previously described [20].

TUNEL assay Sections were probed with rabbit anti-GLUT2 primary antibody (Millipore, Billerica, MA, USA). The secondary antibody used was a Cy5-conjugated goat antirabbit antibody (Jackson Immunoresearch, West Grove, PA, USA). TUNEL staining was used to detect apoptosis with an in situ cell death detection kit (Roche, Indianapolis, IN, USA). Propidium iodide $(2 \mu \mathrm{g} / \mathrm{ml})$ was used as the nuclear counterstain. Images were captured on a confocal microscope (LSM510; Zeiss, Thornwood, NY, USA).

Cytotoxicity assay Islets were stimulated with IFN- $\gamma$ plus TNF- $\alpha(1,000 \mathrm{U} / \mathrm{ml}$ or $2,000 \mathrm{U} / \mathrm{ml})$ for $24 \mathrm{~h}$ and viability of islets was tested by the MTT assay (Sigma-Aldrich, Saint Louis, MO, USA) [24].

Measurements of intracellular peroxides The isolated islets were incubated for $30 \mathrm{~min}$ at $37^{\circ} \mathrm{C}$ with $10 \mu \mathrm{mol} / 1$ dichlorodihydrofluorescein diacetate (Molecular Probes, Eugene, OR, USA). Islets were then dispersed using trypsin treatment and levels of intracellular peroxide were analysed using a FACSCaliber (BD, Franklin Lakes, NJ, USA).

Annexin-V-FITC staining Islets isolated from nontransgenic or $\mathrm{mHo}$-1-transgenic mice were treated with $2,000 \mathrm{U} / \mathrm{ml}$ TNF- $\alpha$ plus $2,000 \mathrm{U} / \mathrm{ml} \mathrm{IFN}-\gamma$ or $20 \mathrm{ng} / \mathrm{ml} \mathrm{IL-}$ $1 \beta$ for $24 \mathrm{~h}$. At the end of treatment, islets were washed and dispersed by cell dissociation buffer. Beta cells were stained with 7-amino-actinomycin D (AAD) and FITC-conjugated annexin-V. Apoptotic cells were determined by annexin-VFITC positive cells.

Statistics Differences in islet graft survival time in $\mathrm{mHo}$-1transgenic and non-transgenic groups were assessed using Kaplan-Meier survival analysis. For the other experiments, differences were compared using Student's one-tailed unpaired and paired $t$ tests. Differences were considered significant at $p<0.05$.

\section{Results}

Expression of mHo-1 in pIns-mHo-1-transfected NIT-1 cells To test the expression potential of transgenic $\mathrm{mHo}-\mathrm{l}$ in insulin-secreting cells, we transfected the $\mathrm{p}$ Ins-mHo-l construct into NIT-1 cells and measured expression of transgenic $\mathrm{mHo}-1$ by RT-PCR and its protein levels by 
western blotting. To determine the level of transgenic $\mathrm{mHo}-\mathrm{l}$ expression and to distinguish it from endogenous $\mathrm{mHo}-\mathrm{l}$, we designed the P1 and P2 primers to amplify the sequence between the second exon of the human insulin gene and the coding region of $\mathrm{mHo}-1$ (Fig. 1a). The $\mathrm{pIns}$ - $\mathrm{mHo}$ - 1 -transfected NIT-1 cells successfully expressed transgenic $\mathrm{Ho}-\mathrm{l}$ at mRNA (Fig. 1b) and protein levels (Fig. 1c). Moreover, the expression of $\mathrm{mHo}-\mathrm{l}$ could be upregulated under high glucose $(20 \mathrm{mmol} / \mathrm{l})$ stimulation for $48 \mathrm{~h}$, suggesting that expression of transgenic $\mathrm{mHo}-\mathrm{l}$ was regulated differentially by the insulin promoter (Fig. 1c). These results clearly demonstrate the expressional availability and feasibility of the $\mathrm{p} I n s-\mathrm{mHo}-1$ construct in NOD beta cells.

a

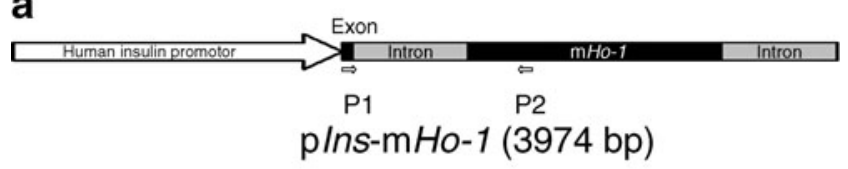

b

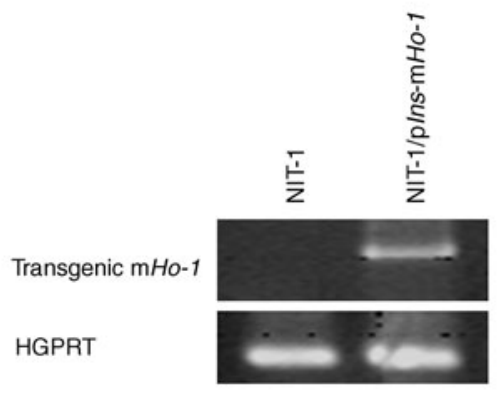

C

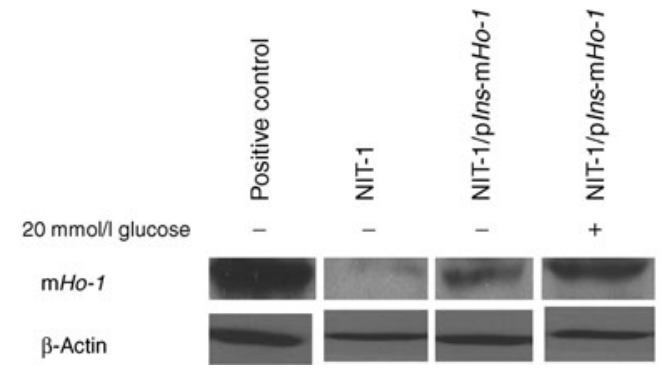

Fig. 1 Construction and expression of the transgene. a Diagram of the transgene construct. The black areas represent exons and the grey areas represent introns. This construct contains two introns adjacent to Ho- 1 to enhance Ho- $\mathrm{l}$ expression and a non-coding exon on the upstream side of the first intron. This can be used to discriminate between $H o-1$ expression encoded by the pIns-mHo- 1 construct and endogenous gene expression using a forward primer that binds the non-coding exon. The entire first non-coding exon followed by the first intron and $16 \mathrm{bp}$ of the second exon of the human insulin gene, which are not translated into protein, were preserved to ensure the stringency of the insulin promoter. A forward primer (P1) in the second exon of the insulin gene and a backward primer (P2) in the coding region of mouse $\mathrm{Ho}-\mathrm{l}$ were designed to evaluate expression of the transgene specifically. The $\mathrm{p} I n s-\mathrm{mHo}-1$ construct was transfected into NIT-1 cells using lipofectamine and transcription and translation of pIns-mHo- 1 were detected by (b) RT-PCR and (c) western blotting. Hypoxanthine-guanine phosphoribosyltransferase (HGPRT) was the internal control for RT-PCR
Generation of pIns-mHo-1-transgenic NOD mice To evaluate directly whether transgenic expression of $\mathrm{mHo}-\mathrm{l}$ in beta cells protects NOD mice from autoimmune diabetes, we generated $\mathrm{p} I n s-\mathrm{mHo}$-1-transgenic mice by microinjecting a pIns-mHo- 1 construct into fertilised NOD eggs. Southern blot analysis revealed that there were one to five copies of the $\mathrm{mHo}-\mathrm{l}$ transgene in the genome of the transgenic founder (Fig. 2a). RT-PCR results indicated that transgenic $\mathrm{mHo}-1$ was expressed specifically in the pancreas of $\mathrm{mHo}$ 1 -transgenic mice (Fig. 2b), confirming the stringent expression of this transgene driven by the insulin promoter. Western blot and immunohistochemical (IHC) analyses demonstrated the presence of HO-1 in the spleen, liver and kidney both in transgenic and non-transgenic control mice (Fig. 2c, d). However, HO-1 levels were significantly higher in the pancreatic islets of the $\mathrm{mHo}$ - - -transgenic mice, but were barely detectable in controls (Fig. 2c, d). These results indicated that levels of endogenous HO-1 in pancreatic islets is very low and confirmed that the insulin promoter used in our system could overexpress $\mathrm{mHo}-1$ accurately in pancreatic islets. Moreover, the overall expression level of $\mathrm{Ho}-1$ in transgenic islets was lower than that in non-transgenic islets stimulated with cobalt protoporphyrin (CoPP), a strong HO-1 inducer (Fig. 2e). These results suggest an expressional difference between insulin promoter-driven and CoPP-induced islets.

Characterisation of the diabetogenic process in $\mathrm{mHo}-1$ transgenic NOD mice and evaluation of $\mathrm{mHo}$-1-transgenic islets following syngeneic islet transplantation To investigate the potential protective effects of tissue-specific expression of transgenic $\mathrm{mHo}-\mathrm{l}$ in autoimmune diabetes, we analysed the severity of insulitis in $\mathrm{mHo}$-1-transgenic $(n=4)$ and non-transgenic mice $(n=4)$ at 14 weeks of age; we also investigated the incidence of spontaneous diabetes in $\mathrm{mHo}-1$-transgenic $(n=30)$ and non-transgenic mice $(n=30)$. The severity of insulitis was reduced significantly, although expression of the $\mathrm{mHo}-1$ transgene did not completely prevent it (Fig. 3a). To further investigate the protective effect of transgenic $\mathrm{mHo}-1$, we analysed the development of spontaneous diabetes. The $\mathrm{mHo}-\mathrm{I}$ transgenic mice were protected significantly from the development of autoimmune diabetes compared with nontransgenic littermates $(p<0.01)$ (Fig. $3 b)$, confirming the advantage of islet-specific $\mathrm{Ho}$-lexpression in preventing autoimmune diabetes in NOD mice.

Transplantation of pancreatic islets into a diabetic recipient is a potential way to cure individuals with type 1 diabetes. To investigate whether transgenic expression of $\mathrm{mHo}-\mathrm{l}$ in transplanted islets could reverse diabetes in recent-onset mouse recipients and protect beta cells against immune attack, we performed islet transplantation. We isolated islets from $\mathrm{mHo}$-1-transgenic or non-transgenic mice and 
a

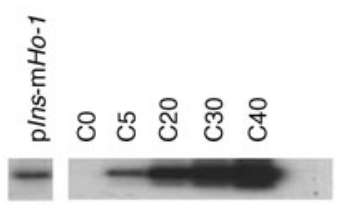

b

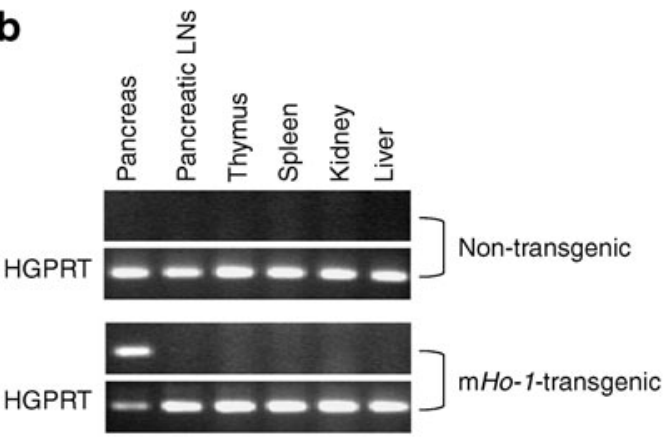

C

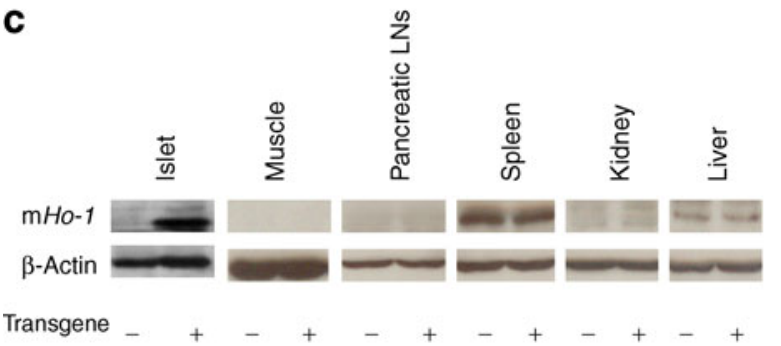

d

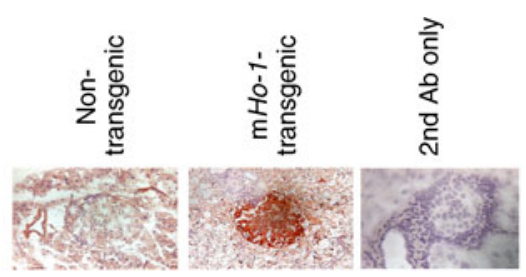

e
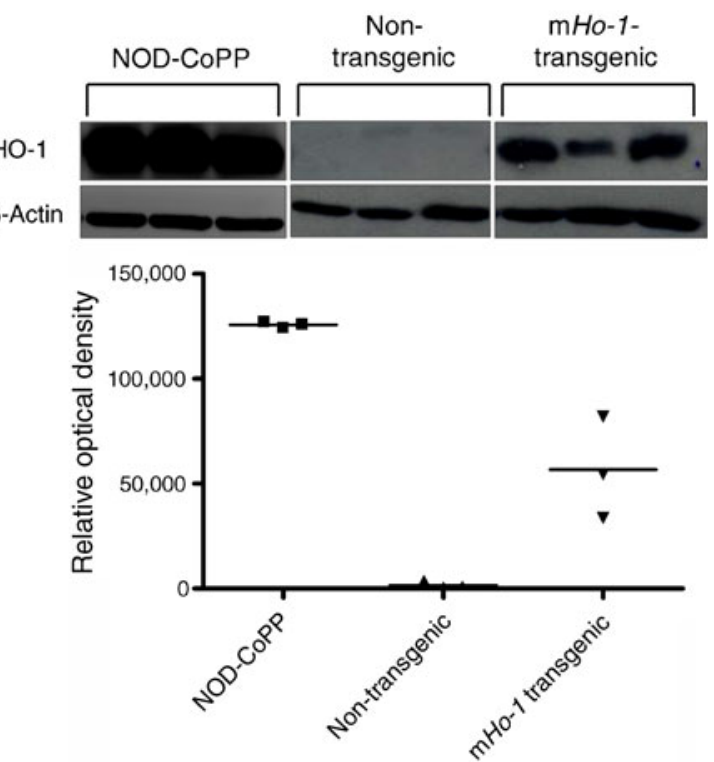

Fig. 2 Generation of $\mathrm{p}$ Ins-mHo-1-transgenic NOD mice. a Southern blot analysis was performed to identify the existence of transgenic $\mathrm{mHo}-\mathrm{l}$ and provided the relative copy number of the $\mathrm{mHo}-\mathrm{l}$ transgene in the founder. $\mathrm{LN}$, lymph node. Islet-specific expression of the $\mathrm{mHo}$ 1 transgene was confirmed by (b) RT-PCR amplification and (c) western blot analysis. White bars, non-transgenic; black bars, $\mathrm{mHo}-1$ transgenic. The transgenic $\mathrm{p} I n s-\mathrm{m} H o-1$ construct and endogenous $\mathrm{mHo}-\mathrm{l}$ transcripts and translated levels from multiple organs of $\mathrm{mHo}$ 1 -transgenic NOD mice or wild type NOD mice were assessed. ${ }^{*} p<$ $0.05 ; * * p<0.01$. Hypoxanthine-guanine phosphoribosyltransferase (HGPRT) and $\beta$-actin served as internal controls for RT-PCR and

implanted them into the left kidney capsule of newly diabetic female NOD recipients. In most recipients implanted with control islets, hyperglycaemia recurred within 7 days after transplantation; the mean graft survival time was 6.643 days. All recipients grafted with transgenic islets maintained them for at least 8 days and the mean graft survival time was 10.875 days (Fig. 3c). These results indicate that the transgenic expression of $\mathrm{mHo}-\mathrm{l}$ in grafted islets significantly prolonged survival of cells in diabetic recipients $(p<0.01)$. To further investigate whether transplantation disturbed transgene expression and how long $\mathrm{mHo}$-1-transgenic islets continue to produce $\mathrm{HO}-1$, we examined the production of HO-1 in graft islets by IHC staining. The $\mathrm{mHo}$-1-transgenic NOD islet grafts at day 8 after transplantation still produced $\mathrm{HO}-1$, with preservation of the islet architecture, and also showed more intact islets with insulin-secreting function (Fig. 3d). In summary, western blotting, respectively. Plus symbol, $\mathrm{mHo}-1$ transgenic mice; minus symbol, normal NOD mice. d Frozen pancreatic sections of control NOD or mHo-1 transgenic NOD mice were stained with anti$\mathrm{mHo}-1$ primary antibody. The group staining with horseradish peroxidase-conjugated secondary antibody $(\mathrm{Ab})$ only served as negative control for immunohistochemistry. e Protein levels of $\mathrm{mHo}$ 1 in NOD islets following CoPP treatment, in normal NOD islets and in transgenic $\mathrm{p} I n s-\mathrm{mHo}-\mathrm{l}$ islets were detected by western blotting and quantified using UN-SCAN-IT gel software (Silk Scientific, Orem, UT, USA). LN, lymph node

expression of transgenic $\mathrm{mHo}-1$ was effective in prolonging islet graft survival, but did not provide permanent protection from recurrence of diabetes.

Lymphocyte and dendritic cell development in mHo-1transgenic NOD mice It is known that an imbalance between Th1 and Th2 cell responses [25], pathological dendritic cells $[26,27]$ and reduced numbers of Treg cells [28] predispose NOD mice to developing autoimmune diabetes. HO-1 can modulate the immune response by inhibiting maturation of dendritic cells and by regulating the functions of Th1 and Treg cells [11-13]. To investigate whether the protective effect of transgenic $\mathrm{mHo}-\mathrm{l}$ works through these immunoregulatory functions, the $\mathrm{mHo}-1$ transgenic NOD mice were crossed with T1/T2 double transgenic NOD mice to generate $\mathrm{T} 1 / \mathrm{T} 2 / m H o-1$ triple transgenic NOD mice. These bear two transgenes: human THY1 
a

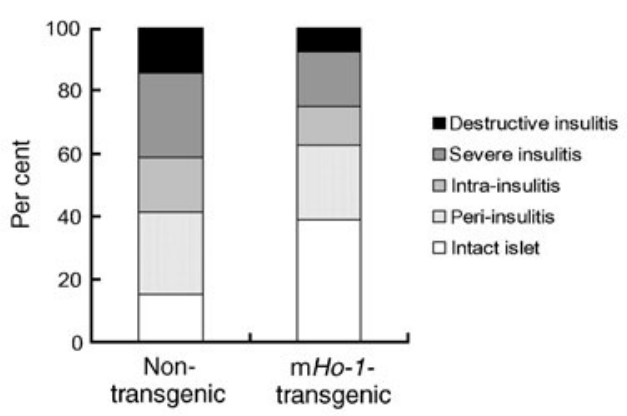

b

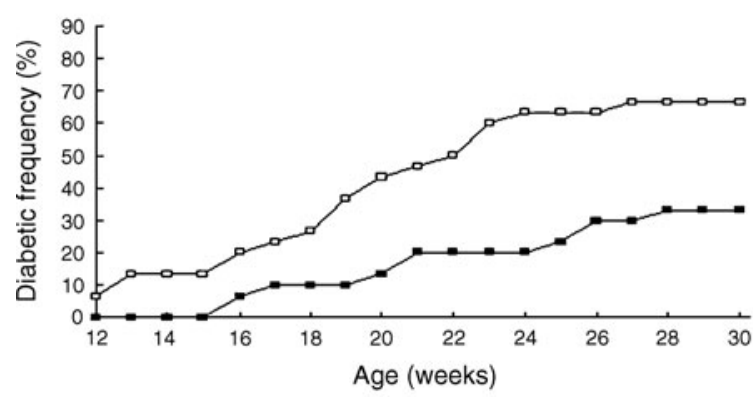

Fig. 3 Diabetogenesis in $\mathrm{mHo}$ - 1 -transgenic NOD mice and protective effects of syngeneic transgenic $\mathrm{mHo}-1$ islet transplantation against autoimmune attack. a The severity of insulitis was examined on haematoxylin- and eosin-stained sections of pancreases from transgenic or control NOD mice at 14 weeks of age. Investigators were blind to the identity of the section. We measured 162 islets from four $\mathrm{mHo}-1$-transgenic NOD mice and 131 islets from four non-transgenic control NOD mice for the severity of insulitis. About $38.89 \%$ of islets from 14-week-old female $\mathrm{mHo}$ - 1 -transgenic NOD mice were free from lymphocyte infiltration, but only $15.01 \%$ in age-matched controls $(p<0.05)$. Only $7.41 \%$ of islets from $\mathrm{mHo}-1$ transgenic NOD mice showed destructive insulitis compared with $14.25 \%$ in controls $(p<0.05)$. b Spontaneous diabetes in female $\mathrm{mHo}$ - 1 -transgenic NOD mice (black squares) $(n=30)$ or their non-transgenic (white squares) control littermates $(n=30)$ was monitored by weekly measurement of glycosuria. Control littermates started to develop

under control of the murine Ifn- $\gamma$ (also known as Ifng) promoter and murine Thyl.1 (also known as Thyl) under control of the murine Il4 promoter [29]. Using these mice, the kinetic development of Th1 and Th2 cells could be measured directly by detecting the presence of human Thy-1 cell surface antigen (Thy1) (a T1 marker) and mouse thymus cell antigen 1, theta (Thy1.1) (a T2 marker), respectively. The distribution of each lymphocyte subpopulation and dendritic cells in the spleen or pancreatic lymph nodes was indistinguishable between the $\mathrm{T} 1 / \mathrm{T} 2 / \mathrm{mHo}-1$ triple and $\mathrm{T} 1 / \mathrm{T} 2$ double transgenic NOD mice (Fig. 4a, b), suggesting that local expression of transgenic $\mathrm{mHo}-1$ did not alter systemic or local lymphocyte and dendritic cell development in NOD

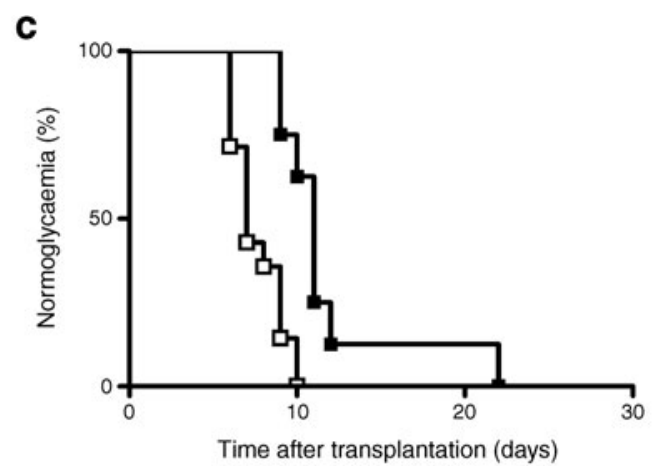

d
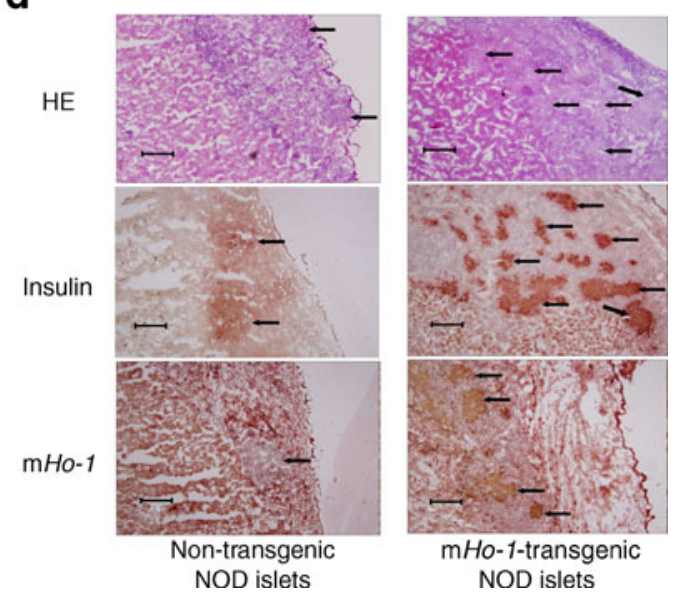

diabetes at 12 weeks of age. In contrast, the first $\mathrm{mHo}$ - 1 -transgenic NOD mouse did not have diabetes until after 15 weeks, indicating a delay in disease onset. At about 30 weeks of age, the diabetic incidence of control mice increased to $66.7 \%$, but that of $\mathrm{mHo}-1$ transgenic NOD mice was still only $33.3 \%$. c The survival duration of $\mathrm{mHo}$-1-transgenic NOD islets (black squares) $(n=8)$ or non-transgenic (white squares) NOD islet grafts $(n=14)$ in the islet-transplanted model of diabetic NOD mice was monitored by testing daily for blood glucose concentrations. d Frozen sections of $\mathrm{mHo}$ - 1 -transgenic NOD and non-transgenic NOD islet grafts at 8 days after transplantation were stained using haematoxylin and eosin (HE). Immunohistochemical analysis was performed to examine production of insulin and murine HO-1. Normal islet structures, insulin and murine HO-1 (black arrows) were observed using light microscopy. Scale bars, $100 \mu \mathrm{m}$. There were three independent experiments for the islet transplantation and at least six sections were analysed in each experiment

mice. Moreover, the percentages of Th1 (CD4/hThy1), Th2 (CD4/mThy1.1) and $\mathrm{CD}^{+} \mathrm{CD} 25^{+}$forkhead box $\mathrm{P} 3$ $(\text { FOXP3 })^{+}$Treg cells in spleen or pancreatic lymph nodes were not significantly different between the T1/T2/mHo-1 triple and T1/T2 double transgenic NOD mice (Fig. 4a-c), indicating that overexpression of $\mathrm{mHo}-\mathrm{l}$ in islets did not suppress systemic or local IFN- $\gamma$-producing cells, or induce IL-4-producing cells. Furthermore, the maturation of dendritic cells and the numbers of Treg cells were not affected by local $\mathrm{mHo}-1$ overexpression.

To further dissect the protective mechanisms in $\mathrm{mHo}-1$ transgenic mice, we characterised the pathogenicity of $\mathrm{T}$ lymphocytes and performed adoptive islet transfer experi- 


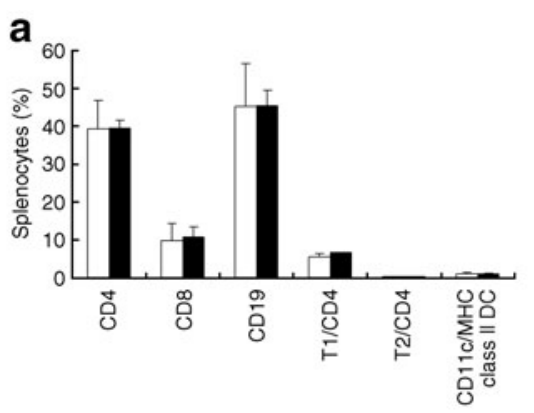

e

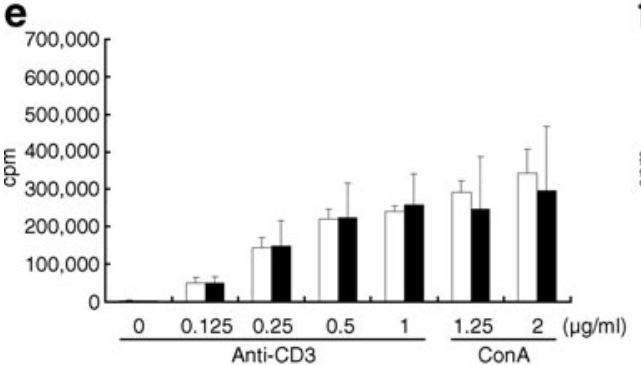

Fig. 4 Lymphocytes, mature dendritic cell composition and $\mathrm{T}$ lymphocyte proliferative ability. a The composition of lymphocytes and mature dendritic cells (DC) in spleen and (b) pancreatic lymph nodes from 8-week-old doubly transgenic (T1/T2, white bars) and triple transgenic (T1/T2/mHo-1, black bars) mice were analysed by flow cytometry. c The FOXP3 CD25 cell populations in CD4 splenocytes and (d) CD4 lymphocytes from 8-week-old nontransgenic (white bars) and $m H o-1$-transgenic (black bars) mice were also analysed by flow cytometry. e The proliferation rates of b

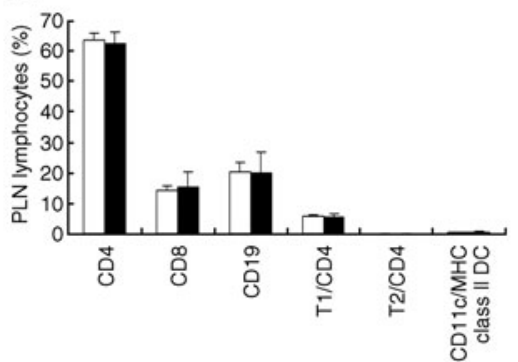

$\mathbf{f}$

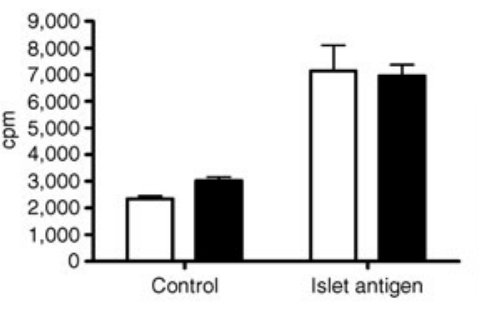

C

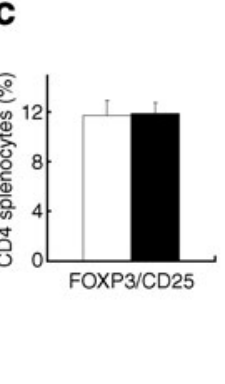

d

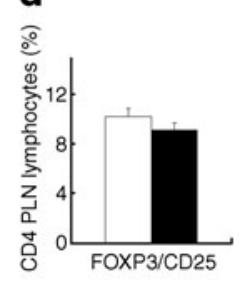

g

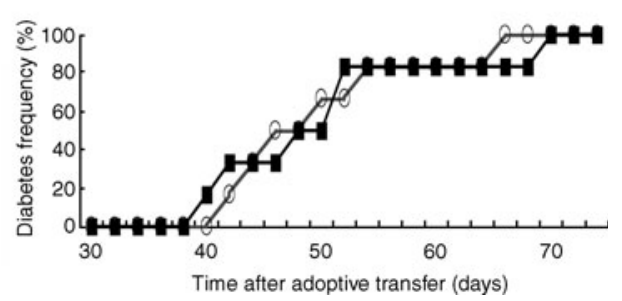

splenocytes from 8-week-old non-transgenic (white bars) and $\mathrm{mHo}$ 1-transgenic (black bars) NOD mice were stimulated by anti-CD3 and Con A, and (f) by NOD islet cell antigens, and assessed by ${ }^{3} \mathrm{H}-$ incorporation. These results are mean \pm SEM from four independent experiments. $g$ The incidence of diabetes in NOD/SCID recipient mice receiving splenocytes from 8 -week-old transgenic $\mathrm{mHo}-1$ NOD mice (black squares) $(n=6)$ or regular NOD mice (white circles) $(n=6)$ was assessed by testing for glycosuria every other day

ments. Splenocytes from transgenic or control mice proliferated equally well upon stimulation with anti-CD3 antibody, concanavalin A or NOD islet antigens (Fig. 4d, e), indicating that the transgenic expression of $\mathrm{mHo}-1$ did not affect the proliferative ability of lymphocytes in antigenspecific or non-specific manners. These results also suggest that transgenic Ho- 1 did not interfere with the function of antigen-presenting cells (Fig. 4d). To further evaluate the pathogenic ability of lymphocytes of $\mathrm{mHo}$-1-transgenic mice, we injected NOD/SCID recipients intravenously with splenocytes from $\mathrm{mHo}$-1-transgenic or non-transgenic mice and compared the progress of diabetes in the two groups. No significant differences were observed between the two groups of recipients (Fig. 4f), indicating that the expression of transgenic $\mathrm{Ho}-\mathrm{l}$ in beta cells did not affect systemic immunity in the NOD mice.

Inflammation and apoptosis in mHo-1-transgenic NOD islets Because HO-1 has significant abilities to counter inflammation, apoptosis and ROS in vitro and in vivo, transgenic beta cells might employ these cytoprotective mechanisms and further prevent the development of autoimmune diabetes. To test this idea, we first compared the expression levels of a panel of proinflammatory and proapoptotic genes between transgenic and control islets by real-time RT-PCR. The expression of inducible nitric oxide synthase (iNos [also known as Nos2]), granzyme B, Illb, Tnf- $\alpha$ (also known as Tnf), Ifng and the chemokines Ccl2, $\mathrm{Ccl} 3, \mathrm{Ccl} 4, \mathrm{Ccl} 5$ and $\mathrm{Cxcl10}$ was significantly decreased in transgenic islets compared with controls (Fig. 5a). Moreover, the expression of proapoptotic genes, such as those encoding for Fas ligand (Fasl) and caspases-3 and -8, was also markedly lower in transgenic islets than in controls (Fig. 5b). These results support the idea that overexpression of Ho-1 effectively downregulates expression of those proinflammatory and proapoptotic genes, thus contributing to cytoprotection in transgenic mice. To further confirm that apoptosis of beta cells was ameliorated in $\mathrm{mHo}$ - $\mathrm{l}$-transgenic mice, we examined the apoptotic beta cells in pancreatic sections by TUNEL assay. The number of apoptotic cells in 6-week-old $\mathrm{mHo}$ - 1 -transgenic islets (Fig. 5d) was significantly lower than that in non-transgenic islets (Fig. 5c) at the same age, indicating transgenic $\mathrm{mHo}-1$-mediated protection. The TUNEL result was also supported by the downregulation of proapoptotic genes such as caspase-3, caspase8 and $\mathrm{Fasl}$ in real-time RT-PCR results of $\mathrm{mHo}-1$-transgenic islets (Fig. 5b). To rule out the possibility that the protective effect in $\mathrm{mHo}$ - 1 -transgenic mice was due to the induction of beta cell proliferation rather than the reduction of beta cell apoptosis, we measured levels of the proliferation marker 
Fig. 5 Expression levels of proinflammatory, proapoptotic and antiapoptotic genes in islets from NOD and $\mathrm{mHo}-1$ transgenic NOD mice. Fresh islets were isolated from $\mathrm{mHo}$ 1 -transgenic NOD mice or regular NOD mice at 6 to 8 weeks of age. RNA was extracted from islets and the levels of expression for (a) proinflammatory cytokine and chemokine genes, and (b) proapoptotic and antiapoptotic genes at the mRNA level were analysed by real-time RT-PCR. The threshold cycle $\left(C_{t}\right)$ value was defined as the number of the PCR cycle at which the fluorescence crossed a fixed threshold above baseline. For relative quantification, the $\Delta \Delta \mathrm{C}_{\mathrm{t}}$ method was used to measure fold changes of cDNA. Expression of endogenous Gapdh was used as normalisation control. Results shown are the mean \pm SEM of four independent groups (each group included islets pooled from three transgenic mHo-1 or nontransgenic NOD mice; $* p<0.05$; $* * p<0.01$. White bars, nontransgenic; black bars, $\mathrm{mHo}$ - 1 transgenic. c The apoptotic beta cells in non-transgenic and (d) $\mathrm{mHo}$ - 1 -transgenic mice were examined by TUNEL assay. Green spots, TUNEL-positive cells in the pancreas section; blue, beta cell marker GLUT2; red, propidium iodide (PI) cell nuclei counter staining. e The level of proliferation marker $\mathrm{Ki}-67$ in the pancreas was examined by IHC analysis. Serial sections were stained with haematoxylin and eosin (HE), and with IHC staining for insulin and $\mathrm{Ki}-67$. Black arrows indicate location of beta cells (insulin-positive cells). HE staining shows that a larger area of islet was infiltrated by lymphocytes in the pancreas of non-transgenic NOD mice than in that of $\mathrm{mHo}$ - 1 -transgenic NOD mice. The production of $\mathrm{Ki}-67$ was mainly located on lymphocytes in the pancreas of non-transgenic NOD mice (black arrow head). Scale bar, $100 \mu \mathrm{m}$ a

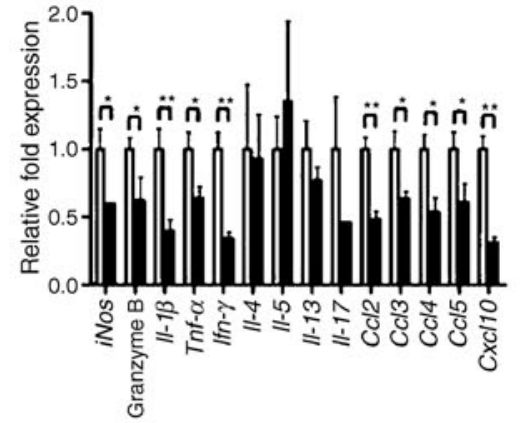

C

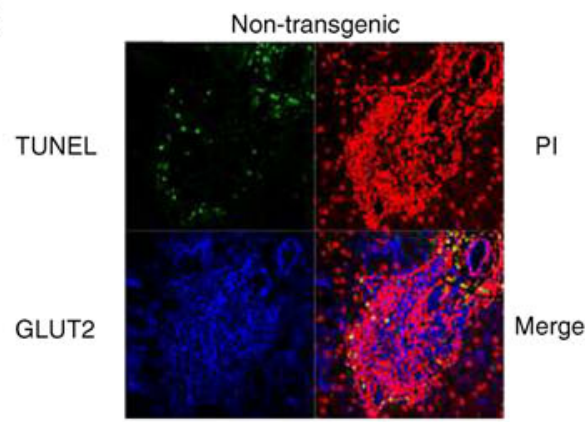

e
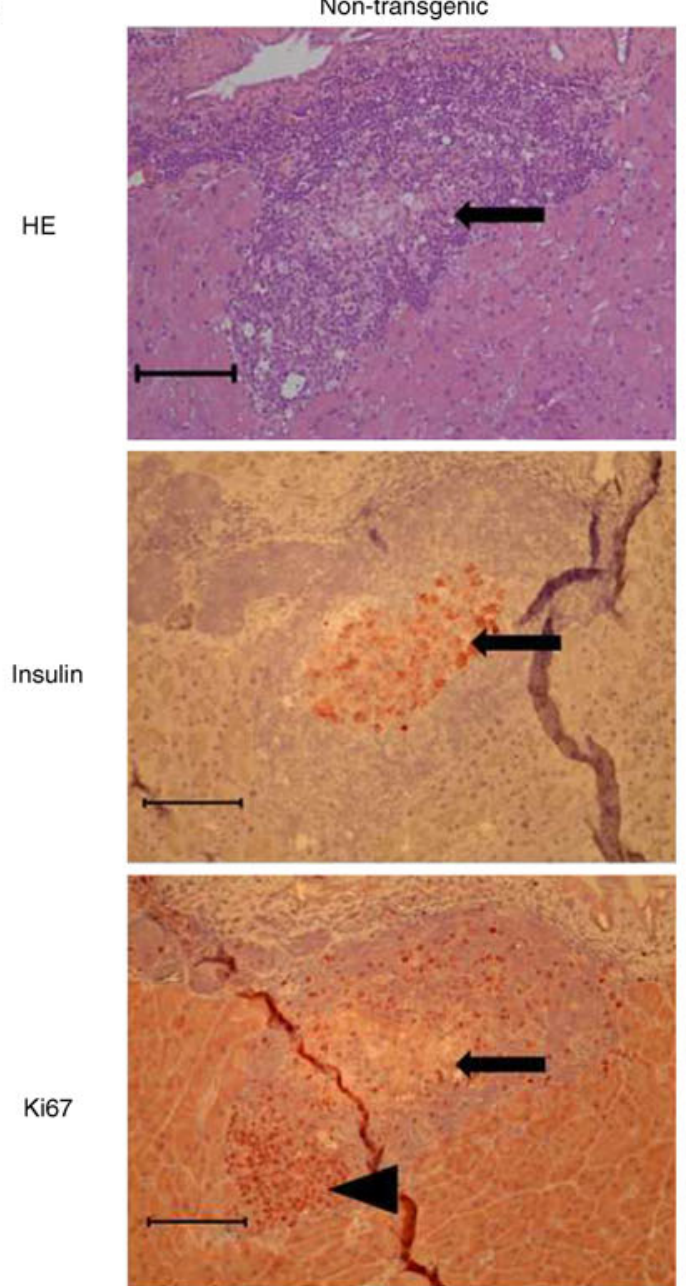

b
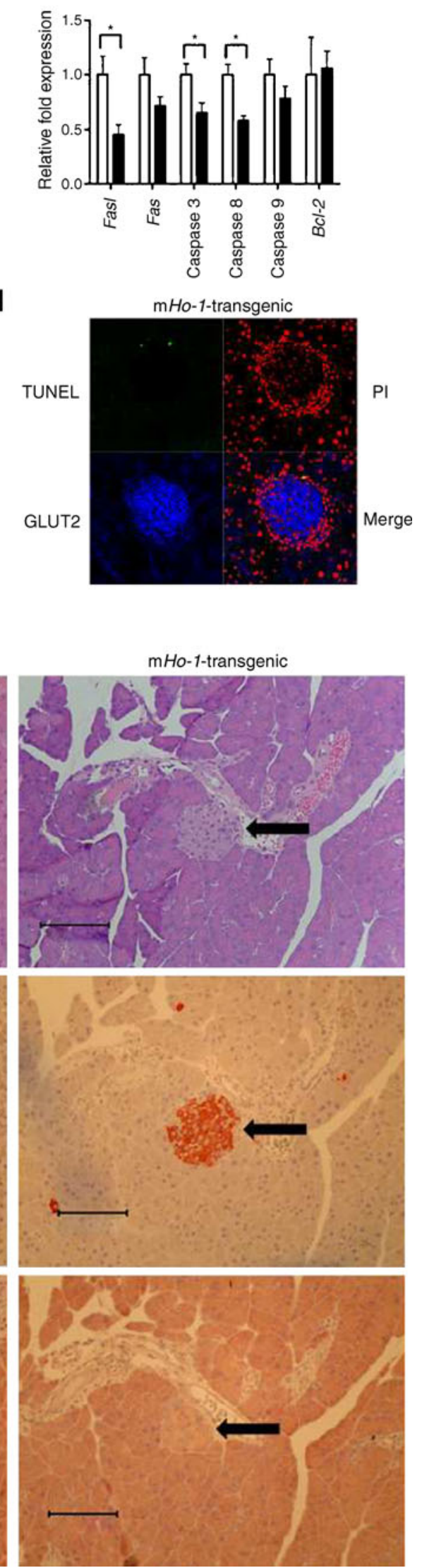
Ki-67 in the pancreas by IHC staining. Serial sections of pancreases from 6-week-old $\mathrm{mHo}$-1-transgenic or nontransgenic mice were analysed by haematoxylin and eosin staining. Insulin and Ki-67 were detected by IHC staining. We observed that there were no apparent proliferation activities in beta cells, either in $\mathrm{mHo}$-1-transgenic or nontransgenic NOD islets, since the positive signal for Ki-67 was not found in areas staining positive for insulin (Fig. 5e). However, there was a strong proliferative signal on the lymphocyte-infiltrating area in non-transgenic islets (Fig. 5e), implying an activating status of those infiltrating lymphocytes. These results further confirm an anti-apoptotic ability mediated by transgenic $\mathrm{mHo}-\mathrm{l}$ in beta cells and indicate that protection is less than likely to be through the proliferation of beta cells themselves.

To further evaluate the antiapoptotic ability of HO-1, we analysed TNF- $\alpha$-induced apoptosis in NIT-1 cells, NIT-1 cells with CoPP treatment or NIT-1 cells transduced with lenti-HO-1. The CoPP-treated NIT-1 cells and Ho-1transduced NIT-1 cells exhibited lower rates of apoptosis than the control NIT-1 or green fluorescent protein (GFP)transduced NIT-1 cells, respectively (Fig. 6a), indicating that NIT-1 cells showing Ho- 1 overexpression can counter apoptotic attack by cytotoxic cytokines. To investigate the antiapoptotic potential of $\mathrm{mHo}$-1-transgenic islets, we isolated islets from 6-week-old mice and detected their ROS/RNS levels. The ROS/RNS levels in $\mathrm{mHo}-1$ transgenic islets were significantly lower than in control islets (Fig. 6b). We propose that ROS production at this age may largely come from islet cells. However, we cannot completely exclude the possibility that these few infiltrating lymphocytes still contribute to ROS production presented in Fig. 6b. Real-time RT-PCR analyses (Fig. 5a, b) revealed that Ifng, Fasl and granzyme B, predominantly expressed in immune cells, were detected from isolated islets, supporting the existence and activating status of the infiltrating immune cells in islets. Nevertheless, the expression levels of those genes in infiltrating immune cells from $\mathrm{mHo}-1$ transgenic mice were downregulated, compared with those in non-transgenic mice, indicating a transgenic HO-1modulated effect on the activating status of lymphocytes. Strikingly, $\mathrm{mHo}$-1-transgenic islets showed higher viability than control islets under TNF- $\alpha$ plus IFN- $\gamma$ treatment $\left(1,000 \mathrm{U} / \mathrm{ml}\right.$ or $\left.2,000 \mathrm{U} / \mathrm{ml},{ }^{*} p<0.05\right)$ (Fig. $6 \mathrm{c}$ ). To determine the antiapoptotic ability of HO-1, we detected annexin-V-positive cells in the islets treated with 2,000 U/ml TNF- $\alpha$ plus $2,000 \mathrm{U} / \mathrm{ml}$ IFN- $\gamma$. Apoptotic cells in beta cells isolated from $\mathrm{mHo}-1$-transgenic mice were significantly fewer than in beta cells isolated from non-transgenic littermate $(* p<0.05)$ (Fig. 6d). Thus, the $\mathrm{mHo}$-1-transgenic islets had strong antiapoptotic ability against cytotoxic cytokines. This could contribute to protection against autoimmune diabetes and prolong survival of transplanted islet grafts in NOD mice. We further examined the protective effect of HO-1 on IL-1 $\beta$-induced beta cell apoptosis. Our data revealed that although the percentage of annexin-V-FITC-positive beta cells in $\mathrm{mHo}$ - 1 -transgenic mice was slightly lower than that in non-transgenic mice, the difference was not statistically significant (Fig. 6e). These results suggest that transgenic HO-1-mediated protection is much less significant in islets treated with IL- $1 \beta$ than in islets treated with TNF- $\alpha$ und IFN- $\gamma$. To further investigate the transgenic $\mathrm{Ho}$-1-mediated protective mechanism, we evaluated the status of phosphorylated signal transducer and activator of transcription 1 (STAT-1), inhibitory protein of NF-KB (IKB) and nuclear factor kappa-light-chain-enhancer of activated $\mathrm{B}$ cells $(\mathrm{NF}-\mathrm{kB})$ (p65) in islets isolated from non-transgenic or $\mathrm{mHo}-1$ transgenic mice by western blot. Our result revealed no significant differences in the phosphorylated status of NF$\mathrm{KB}$ or IKB between non-transgenic and $\mathrm{mHo}-1$-transgenic mice. However, the amount of phosphorylated STAT-1 was lower in the islets of $\mathrm{mHo}-1$-transgenic mice (Fig. 6f). This result suggests that transgenic $\mathrm{Ho}-1$-mediated beta cell protection is dependent on the IFN- $\gamma-$ STAT- 1 pathway.

\section{Discussion}

In NOD mice, transient and systemic overexpression of $\mathrm{mHo}-1$ by viral transduction or using CoPP induction can successfully reduce the degree of insulitis and decrease the frequency of spontaneous diabetes because both systemic autoimmunity and ROS production by the pancreas are suppressed [14, 30]. However, it is unclear whether constitutive production of HO-1 in a beta cell-specific manner could prevent autoimmune diabetes and prolong graft survival following syngeneic islet transplantation. To test this idea, we first established $\mathrm{mHo}$ - 1 -transgenic NOD mice under control of the insulin promoter [31]. These animals produce high levels of HO-1 in pancreatic beta cells from birth. The degree of insulitis was milder, and disease kinetics and incidence in $\mathrm{mHo}$-1-transgenic mice were ameliorated compared with non-transgenic littermates. These results demonstrate that the local and persistent expression of $\mathrm{m} H o-1$ in pancreatic beta cells offers protective effects against autoimmune diabetes.

Islet transplantation is a better therapeutic strategy than administration of exogenous insulin for the treatment of patients with type 1 diabetes, as it can adjust blood glucose to an adequate level in 'real time', avoiding secondary complications [32]. However, autoimmune attack and allograft rejection are major problems leading to destruction of islet grafts. Autoimmune attack occurred faster and was more severe than allograft rejection [33]. Induction of HO-1 by viral transduction or drugs can alleviate allograft 

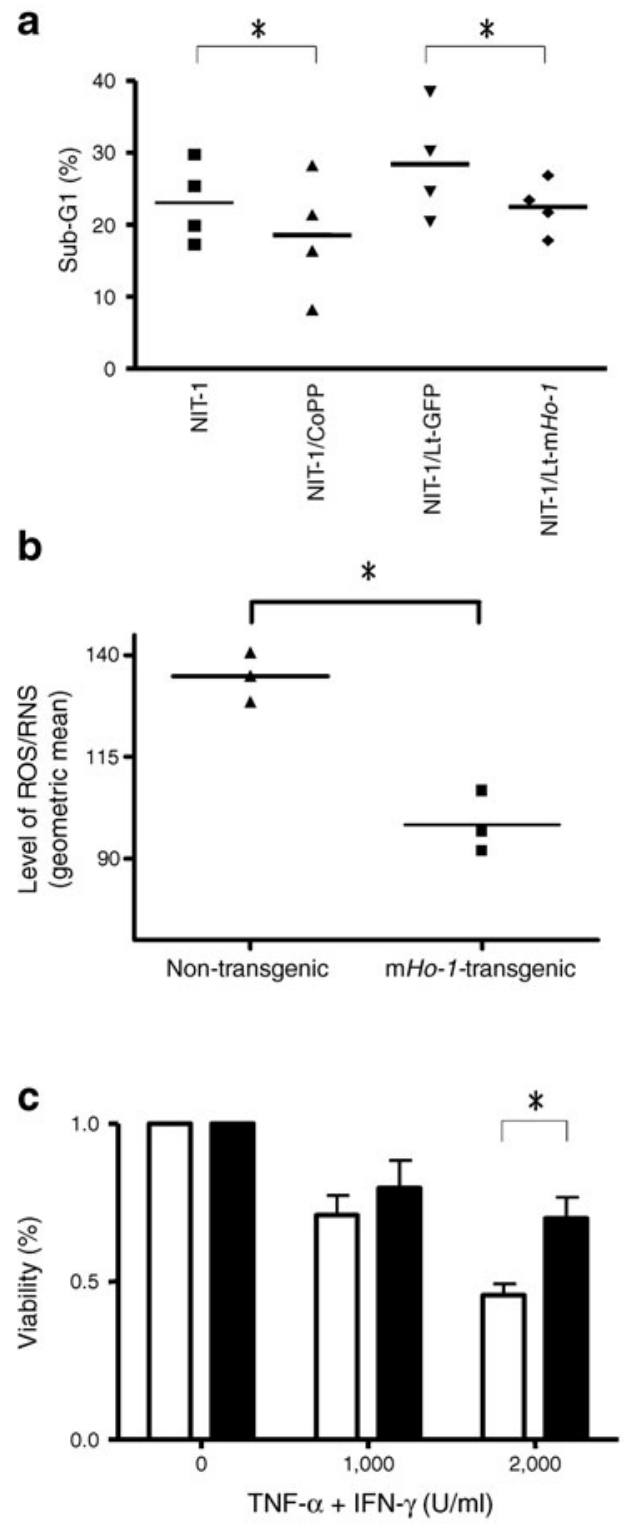

Fig. 6 Anti-apoptotic ability of NIT-1/lentivirus-mHo-1 and $\mathrm{mHo}-1$ transgenic islets. a NIT-1 cells, NIT-1 cells treated with CoPP $(100 \mu \mathrm{mol} / \mathrm{l})(\mathrm{NIT}-1 / \mathrm{CoPP})$, NIT-1 cells transduced with enhanced GFP using lentivirus (NIT-1/Lt-GFP) and NIT-1 cells transduced with $\mathrm{mHo}-1$ using lentivirus (NIT-1/Lt-mHo-1) were treated with TNF- $\alpha(500 \mathrm{U} / \mathrm{ml})$ in culture medium for $24 \mathrm{~h}$. The viabilities shown are the means from four independent experiments; ${ }^{*} p<0.05$. b The ROS/RNS levels of fresh islets from transgenic $\mathrm{mHo}-1$ NOD mice or non-transgenic NOD mice at 6 to 8 weeks of age were detected with dichlorodihydrofluorescein diacetate. Results shown are three independent experiments (each experiment included islets pooled from three transgenic $\mathrm{mHo}-\mathrm{l}$ or nontransgenic NOD mice); ${ }^{*} p<0.05$. c Fresh islets from transgenic $\mathrm{mHo}-1$ NOD (black bars) mice or non-transgenic NOD (white bars) mice at 6 to 8 weeks of age were treated for $24 \mathrm{~h}$ with TNF- $\alpha$ plus IFN- $\gamma(1,000 \mathrm{U} / \mathrm{ml}$ or $2,000 \mathrm{U} / \mathrm{ml}$ ). Viability is shown as the mean \pm SEM from four independent experiments (each group included islets pooled from three transgenic $\mathrm{mHo}-1$ or non-transgenic NOD mice); ${ }^{*} p<0.05$. d Detection of apoptotic cells. Islets isolated from non-transgenic or $\mathrm{mHo}-1$
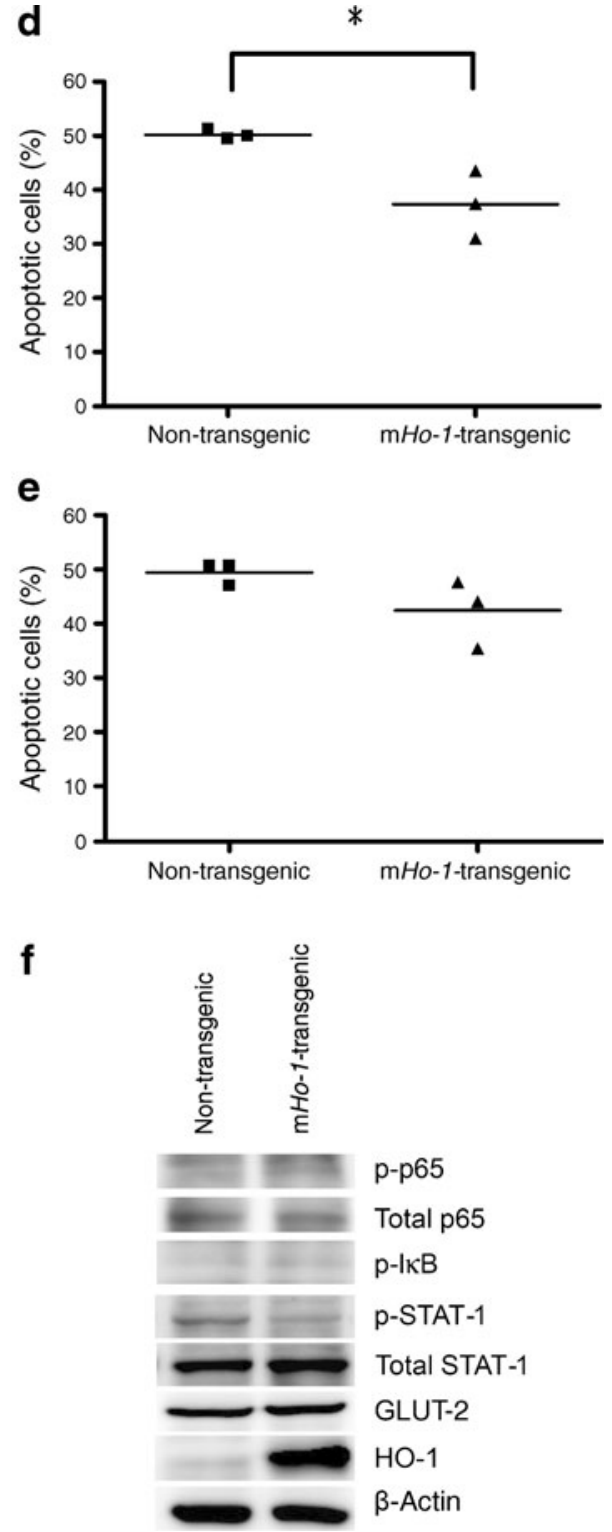

transgenic NOD mice were treated with $2,000 \mathrm{U} / \mathrm{ml}$ TNF- $\alpha$ plus $2,000 \mathrm{U} / \mathrm{ml} \mathrm{IFN}-\gamma$ for $24 \mathrm{~h}$. After the end of treatment, islets were washed and dispersed by cell dissociation buffer. Beta cells were stained with 7-AAD and FITC-conjugated annexin-V. Apoptotic cells were determined by annexin-V-FITC positive cells. Data are shown are mean \pm SEM from three independent experiments (each group included islets pooled from two transgenic $\mathrm{mHo}-\mathrm{l}$ or non-transgenic NOD mice); $* p<0.05$. e Evaluation of the protective effect of HO- 1 on IL- $1 \beta$ induced beta cell apoptosis. Islets isolated from non-transgenic or $\mathrm{mHo}$ - 1 -transgenic NOD mice were treated with $20 \mathrm{ng} / \mathrm{ml} \mathrm{IL}-1 \beta$ for $24 \mathrm{~h}$. At the end of treatment, islets were washed and dispersed by cell dissociation buffer. Beta cells were then treated as above (d). Data are shown as the mean \pm SEM from three independent experiments (each group included islets pooled from two transgenic $\mathrm{mHo}-1$ or non-transgenic NOD mice). $\mathbf{f}$ The status of phosphorylated STAT-1, IKB and NF-kB (p65) in islets isolated from non-transgenic or $\mathrm{mHo}$-1-transgenic NOD mice was determined by western blot 
rejection following islet transplantation [18, 34], but the potential for beta cell-specific production of HO-1 in protecting against autoimmune attack has not yet been evaluated. Our results here are the first to demonstrate that HO-1 overproduction in beta cells effectively prolongs graft survival. This suggests that local production of HO-1 helps protect against recurrence of autoimmune diabetes. However, this protective effect is not complete or lifelong; this may be because expression of the Ho- 1 transgene is varied and insufficient. This point is supported by some evidence that the expression level of HO-1 in cells affects its cytoprotective effects [35].

Accumulating evidence has shown that not only Th1 cells, but also mature dendritic cells and Treg cells are related to the development of autoimmune diabetes in NOD mice. Dendritic cells in NOD mice have abnormally high immunostimulatory and Th1-inducing abilities. In addition, inhibition of iDC maturation can also suppress immune response and induce peripheral tolerance in NOD mice. A decline in the Treg cell population was also noted in NOD mice and transfer of polyclonal $\mathrm{CD} 4^{+} \mathrm{CD} 25^{+} \mathrm{FOXP}^{+}$Treg cells has been demonstrated to prevent diabetes in NOD mice [28]. A previous study has reported that systemic expression of $\mathrm{Ho}-1$ by AAV-HO-1 transduction suppressed the population and activities of systemic Th1 cells by decreasing the population of mature dendritic cells in NOD mice, but this did not affect systemic Th2 and Treg cells [14]. However, the populations of lymphocytes such as CD4 including Th1 and Th2, CD8, Treg cells and mature dendritic cells in spleen or pancreatic lymph nodes were indistinguishable between transgenic and control mice in our study. We further evaluated the diabetogenic ability of lymphocytes in transgenic mice by adoptive transfer experiments. The result indicated an equal diabetogenic effect of lymphocytes from both mouse strains. These data suggest that transgenic $\mathrm{Ho}$-1-mediated protection may not act by modulating systemic autoimmunity.

Previous studies have indicated that HO-1 counteracts inflammation, including reduction of inducible nitric oxide synthase, chemokines and cytokine levels in islets and other cells [36-39]. Using real-time RT-PCR, we found lower expression of inflammatory chemokines in islets from transgenic mice. Our results support the idea that overexpression of $\mathrm{Ho}-\mathrm{l}$ in beta cells decreases the secretion of inflammatory chemokines in islets and hence reduces the number of lymphocytes attacking the islets. The insulitis score of transgenic mice further supports this conclusion. Besides, HO-1 also contributes to cytoprotection by reducing apoptosis. Tobiasch et al. demonstrated that CoPPinduced $\beta$ TC3 cells (an insulinoma cell line) with high HO-1 levels were able to counteract the apoptosis of beta cells caused by various stimuli through activation of the p38 mitogen-activated protein kinase pathway [40]. Our TUNEL assay data apparently support those findings. Moreover, human islets highly expressing $H o-1$ can resist apoptosis induced by TNF- $\alpha$ and cycloheximide [18] through downregulation of the proapoptotic proteins caspase-3 and -8 , and by upregulation of the antiapoptotic proteins apoptosis regulator $\mathrm{Bcl}-2$ (BCL-2) and apoptosis regulator $\mathrm{Bcl}-\mathrm{xL}$ (BCL-XL) [41, 42]. Similarly, caspase-3 and -8 were also suppressed in $\mathrm{mHo}-1$-transgenic islets in our results. NIT-1 cells with CoPP treatment or transduced with lenti-Ho-1 showed better protection against TNF- $\alpha$-mediated cell death. Similar results were also observed in $\mathrm{mHo}-1$ transgenic islets, further demonstrating the antiapoptotic effect of transgenic $\mathrm{Ho}-1$.

In this study, we have demonstrated that transgenic Ho- 1 in pancreatic beta cells protected against autoimmune diabetes in NOD mice by increasing the ability of islets to counter apoptosis and inflammation without changing the status of systemic immunity. These findings further suggest that genetic manipulation of HO-1 levels in islets could be a potential therapeutic strategy to treat type 1 diabetes and prevent disease recurrence following islet transplantation.

Acknowledgements This work was supported by the National Science Council, Taiwan, Republic of China (NSC-96-2628-B-016002-MY3, NSC98-3112-B-016-002 and NSC99-3112-B-016-001 to H.-K. Sytwu) and research grant from Tri-Service General Hospital, Taiwan, Republic of China (TSGH-C98-12-S01 and TSGH-C99-01112-S01 to H.-K. Sytwu). It was also supported in part by the C.Y. Foundation for Advancement of Education, Sciences and Medicine.

Duality of interest The authors declare that there is no duality of interest associated with this manuscript.

\section{References}

1. Atkinson MA, Eisenbarth GS (2001) Type 1 diabetes: new perspectives on disease pathogenesis and treatment. Lancet 358 : 221-229

2. Tisch R, McDevitt H (1996) Insulin-dependent diabetes mellitus. Cell 85:291-297

3. Wicker LS, Todd JA, Peterson LB (1995) Genetic control of autoimmune diabetes in the NOD mouse. Annu Rev Immunol 13:179-200

4. Kawasaki E, Abiru N, Eguchi K (2004) Prevention of type 1 diabetes: from the view point of beta cell damage. Diabetes Res Clin Pract 66(Suppl 1):S27-S32

5. Delaney CA, Tyrberg B, Bouwens L et al (1996) Sensitivity of human pancreatic islets to peroxynitrite-induced cell dysfunction and death. FEBS Lett 394:300-306

6. Lenzen S (2008) Oxidative stress: the vulnerable beta-cell. Biochem Soc Trans 36:343-347

7. Suarez-Pinzon WL, Mabley JG, Strynadka K et al (2001) An inhibitor of inducible nitric oxide synthase and scavenger of peroxynitrite prevents diabetes development in NOD mice. J Autoimmun 16:449-455

8. Tenhunen R, Marver HS, Schmid R (1969) Microsomal heme oxygenase. Characterization of the enzyme. J Biol Chem 244:6388 6394 
9. Maines MD (1997) The heme oxygenase system: a regulator of second messenger gases. Annu Rev Pharmacol Toxicol 37:517554

10. Katori M, Busuttil RW, Kupiec-Weglinski JW (2002) Heme oxygenase-1 system in organ transplantation. Transplantation 74:905-912

11. Chauveau C, Remy S, Royer PJ et al (2005) Heme oxygenase-1 expression inhibits dendritic cell maturation and proinflammatory function but conserves IL-10 expression. Blood 106:1694-1702

12. Kapturczak MH, Wasserfall C, Brusko T et al (2004) Heme oxygenase-1 modulates early inflammatory responses: evidence from the heme oxygenase-1-deficient mouse. Am J Pathol 165:1045-1053

13. Choi BM, Pae HO, Jeong YR et al (2005) Critical role of heme oxygenase-1 in Foxp3-mediated immune suppression. Biochem Biophys Res Commun 327:1066-1071

14. Hu CM, Lin HH, Chiang MT et al (2007) Systemic expression of heme oxygenase- 1 ameliorates type 1 diabetes in NOD mice. Diabetes 56:1240-1247

15. Yet SF, Tian R, Layne MD et al (2001) Cardiac-specific expression of heme oxygenase-1 protects against ischemia and reperfusion injury in transgenic mice. Circ Res 89:168-173

16. Ke B, Buelow R, Shen XD et al (2002) Heme oxygenase 1 gene transfer prevents CD95/Fas ligand-mediated apoptosis and improves liver allograft survival via carbon monoxide signaling pathway. Hum Gene Ther 13:1189-1199

17. Niimi M, Takashina M, Takami $\mathrm{H}$ et al (2000) Overexpression of heme oxygenase- 1 protects allogeneic thyroid grafts from rejection in naive mice. Surgery 128:910-917

18. Li YX, Li G, Dong WP et al (2006) Protection of human islets from induction of apoptosis and improved islet function with HO1 gene transduction. Chin Med J (Engl) 119:1639-1645

19. Verdaguer J, Schmidt D, Amrani A et al (1997) Spontaneous autoimmune diabetes in monoclonal $\mathrm{T}$ cell nonobese diabetic mice. J Exp Med 186:1663-1676

20. Lin GJ, Huang SH, Chen YW et al (2009) Melatonin prolongs islet graft survival in diabetic NOD mice. J Pineal Res 47:284292

21. Wang CJ, Chou FC, Chu CH et al (2008) Protective role of programmed death 1 ligand 1 (PD-L1) in nonobese diabetic mice: the paradox in transgenic models. Diabetes 57:1861-1869

22. Chou FC, Sytwu HK (2009) Overexpression of thioredoxin in islets transduced by a lentiviral vector prolongs graft survival in autoimmune diabetic NOD mice. J Biomed Sci 16:71

23. Shieh SJ, Chou FC, Yu PN et al (2009) Transgenic expression of single-chain anti-CTLA-4 Fv on beta cells protects nonobese diabetic mice from autoimmune diabetes. J Immunol 183:2277-2285

24. Janjic D, Wollheim CB (1992) Islet cell metabolism is reflected by the MTT (tetrazolium) colorimetric assay. Diabetologia 35:482485

25. Liblau RS, Singer SM, McDevitt HO (1995) Th1 and Th2 CD4+ $\mathrm{T}$ cells in the pathogenesis of organ-specific autoimmune diseases. Immunol Today 16:34-38
26. Banchereau J, Steinman RM (1998) Dendritic cells and the control of immunity. Nature 392:245-252

27. Banchereau J, Briere F, Caux C et al (2000) Immunobiology of dendritic cells. Annu Rev Immunol 18:767-811

28. Pop SM, Wong CP, Culton DA et al (2005) Single cell analysis shows decreasing FoxP3 and TGFbeta1 coexpressing CD4+CD25+ regulatory $\mathrm{T}$ cells during autoimmune diabetes. J Exp Med 201: $1333-1346$

29. Hung JT, Liao JH, Lin YC et al (2005) Immunopathogenic role of TH1 cells in autoimmune diabetes: evidence from a T1 and T2 doubly transgenic non-obese diabetic mouse model. J Autoimmun 25:181-192

30. Li M, Peterson S, Husney D et al (2007) Interdiction of the diabetic state in NOD mice by sustained induction of heme oxygenase: possible role of carbon monoxide and bilirubin. Antioxid Redox Signal 9:855-863

31. Sung HH, Juang JH, Lin YC et al (2004) Transgenic expression of decoy receptor 3 protects islets from spontaneous and chemicalinduced autoimmune destruction in nonobese diabetic mice. J Exp Med 199:1143-1151

32. Gaglia JL, Shapiro AM, Weir GC (2005) Islet transplantation: progress and challenge. Arch Med Res 36:273-280

33. Okitsu T, Bartlett ST, Hadley GA et al (2001) Recurrent autoimmunity accelerates destruction of minor and major histoincompatible islet grafts in nonobese diabetic (NOD) mice. Am J Transplant 1:138-145

34. Pileggi A, Molano RD, Berney $T$ et al (2005) Prolonged allogeneic islet graft survival by protoporphyrins. Cell Transplant 14:85-96

35. Choi BM, Kim BR (2008) Upregulation of heme oxygenase-1 by brazilin via the phosphatidylinositol 3-kinase/Akt and ERK pathways and its protective effect against oxidative injury. Eur $\mathrm{J}$ Pharmacol 580:12-18

36. Datta D, Dormond O, Basu A et al (2007) Heme oxygenase-1 modulates the expression of the anti-angiogenic chemokine CXCL-10 in renal tubular epithelial cells. Am J Physiol Renal Physiol 293:F1222-F1230

37. Springer TA (1994) Traffic signals for lymphocyte recirculation and leukocyte emigration: the multistep paradigm. Cell 76:301314

38. Morse D, Choi AM (2002) Heme oxygenase-1: the "emerging molecule" has arrived. Am J Respir Cell Mol Biol 27:8-16

39. Yang NC, Lu LH, Kao YH et al (2004) Heme oxygenase-1 attenuates interleukin-1beta-induced nitric oxide synthase expression in vascular smooth muscle cells. J Biomed Sci 11:799-809

40. Tobiasch E, Gunther L, Bach FH (2001) Heme oxygenase-1 protects pancreatic beta cells from apoptosis caused by various stimuli. J Investig Med 49:566-571

41. Wen T, Wu ZM, Liu Y et al (2007) Upregulation of heme oxygenase1 with hemin prevents D-galactosamine and lipopolysaccharideinduced acute hepatic injury in rats. Toxicology 237:184-193

42. Wang H, Lee SS, Dell'Agnello C et al (2006) Bilirubin can induce tolerance to islet allografts. Endocrinology 147:762-768 